\title{
Evaluating information technology in teaching and learning
}

\author{
N. JOHN CASTELLAN, JR. \\ Indiana University, Bloomington, Indiana
}

\begin{abstract}
The effectiveness of instructional technology depends on appropriate evaluation of the technology, with special focus on outcomes. Because evaluation assesses how effective the technology is in enabling learners to master a particular subject, what students learn becomes an important criterion for evaluation. But how and when to assess learning and comprehension is an important and continuing problem. This paper deals with strategic evaluation, which emphasizes technical accuracy, pedagogical soundness, substantive fidelity, integrative flexibility, and cyclic improvement. Effective strategic evaluation is a continuing process-ranging from querying immediate comprehension, to modifying instruction, to assessing long-term effects.
\end{abstract}

The effectiveness of instruction depends on an appropriate evaluation of that instruction. Evaluation has several components, perhaps the most important of which is the evaluation of outcomes. As a result, what students learn becomes an important criterion for evaluation. But how and when to assess learning and comprehension is an important and continuing problem. Do we evaluate just at the time at which the student learns an important concept-say, at the end of a class; or at the end of the course-say, in a final exam; or by considering a portfolio of products that the student develops over a period of years? Clearly, the effective evaluation of instruction is a continuing process, which ranges from queries about immediate comprehension to the assessment of long-term effects.

In this paper, I will sometimes appear to refer to instructional software and information technology interchangeably. This is not because I consider the two to be equivalent, but because the evaluation of instructional software has a long history, and it is sometimes simpler to refer to it. However, the use of instructional software is only a small part of the rapidly growing genre of information technologies used in instruction. While instructional software is one type of information technology that can be used in teaching and learning, information technology embraces a wide range of media, including software, CD-ROM, interactive video, and sound. As I survey the new information technologies that are available to educators, I am convinced that effective evaluation is essential, and some of the lessons that we have learned about the effective use of instructional software also apply to all aspects of information technology in education. Moreover, as new and more sophisticated information technologies become available, it is even more critical that

Requests for reprints should be addressed to the author at the Department of Psychology, Indiana University, Bloomington, IN 47405 (e-mail: castellan@indiana.edu). appropriate evaluations be done if we are to make intelligent and effective use of the media.

It is especially heartening to hear the discussion of evaluation presented in this session. Duncan (1993), Ransdell (1993), and Welsh (1993) have described not only the importance of evaluation, but the critical need for it to be done effectively. I think that we all share the vision that information technology has the power to transform teaching and learning, but that it cannot do so without evaluation. From different academic environments and from rather different experiences, each has identified an important role for evaluation. In this presentation, I will take a different, yet complementary, view of evaluation.

The evaluation of instructional software or the use of information technology-to judge from my discussions with faculty genuinely concerned about the quality of instruction-is all too often not done, done poorly, or done at the wrong time. This observation has led me to develop a series of questions and issues that should encourage more and better evaluation. These views have grown out of several years of evaluating technology for my own instructional use and learning of others' use of technology. Some views have been influenced by my experience as a judge for the EDUCOM software awards program-an experience that not only exposed me to a large variety of instructional applications and documentation of their evaluation, but gave me the opportunity to discuss and debate some of these ideas with others more insightful and experienced than I on matters dealing with the instructional application of technology and its evaluation. Although I have discussed the effective use of instructional technology and its evaluation before (e.g., Castellan, 1986, 1987a, 1988), I find that those earlier views must be refined and expanded in light of new developments and experience.

The theme that I would like to stress is that the effective evaluation of instructional software and technology is a continuing and dynamic process that is never complete and may change in character over time. Traditional 
evaluation methods are problematic, especially if the use of technology challenges our traditional assumptions about what should be learned. Proper evaluation begins with the designing of instructional materials, and it is never really complete. In this presentation, I shall consider some questions that should be asked at various points in the process by those responsible for the supervision or orchestration of learning experiences. These questions can be loosely embraced by a process or attitude that is called strategic evaluation.

\section{STRATEGIC EVALUATION}

In the evaluation of any technology for use in instruction, several questions can (and should) be asked. Some have argued that these criteria do not matter, and that the sole criterion for success is whether "it works." I would argue that the determination of whether the technology works is in fact evaluation against a criterion that, although it may not be well articulated, nonetheless can be judged. My goal is to provide a set of criteria that can be used in evaluating instructional software and educational technology in general. These criteria address different aspects of the technology and its use: technical accuracy, pedagogical soundness, substantive fidelity, integrative flexibility, and cyclic improvement. As noted earlier, strategic evaluation is an attitude that influences the way in which we look at instructional technologies. Depending on the context, some criteria may be more important than others, but none should be ignored.

\section{Technical Accuracy}

Does the software execute correctly? Will it work on the platforms that students will use? If the application is used in a departmental computer cluster or on a small network, this may be easy to determine. But if the technology is to be used by students at remote sites, particular hardware configurations will differ widely and it will become crucial to ensure that students are not frustrated by an inability to use the technology. Technical accuracy seems relatively easy to assess, but often it is difficult to achieve. Achieving it requires both time and expertise with the different platforms that students are likely to encounter. It is also a form of evaluation discussed in depth in manuals dealing with the development of instructional technology.

\section{Pedagogical Soundness}

Does the software use appropriate pedagogy? Here the question that needs to be considered is whether the designed system works well in conveying the content and concepts to be learned. There are many fine books about the design of instructional materials. Some are expressly intended for the development of instructional software (e.g., Alessi \& Trollip, 1985; Jonassen, 1988; Lockard, 1992; Steinberg, 1991). In addition, there is a growing number of books on the design of effective humancomputer interactions (e.g., Carroll, 1991). However, as good as such books are for people interested in developing materials, people interested in effective instructionwhether or not it involves technology-should know the fundamental behavioral and cognitive processes involved in learning, thinking, and problem solving. Excellent overviews are available (e.g., Baron \& Sternberg, 1987; Gagné, 1985; Glover, Ronning, \& Bruning, 1990; Hill, 1982; Mayer, 1987). In his conference presentation, Tennyson (1993) outlines a system that intimately integrates the assessment of cognitive processing and the development of instructional technology.

Many important aspects of pedagogy could be considered. The following questions that should be asked about instructional technology have been phrased to encourage instructors to delve deeply into their motivation for teaching particular topics and concepts. The questions that constitute the following list are not independent. Rather, they are highly interrelated, and it would be difficult to identify one as more important than another.

Are instructional goals articulated clearly for the student? If students are to develop a useful schema for the knowledge or skills to be acquired, it is essential that the students know what the goals are. Although it may be tempting simply to leave the articulation of goals for the student to discover, only a small percentage of students are likely to correctly discern the goals, and, even then, not necessarily at the appropriate time. Students who know the goals can monitor their progress toward those goals and can gain confidence and satisfaction as they recognize their progress in achieving them.

Is it clear where technology ends and substance begins? This is a special problem in many areas of psychology. For example, if the goal is to teach various structures in the human brain, then the distinction is probably clear to the student. However, some of our applications in psychology are designed to illustrate concepts that are intimately tied to the use of the computer. For example, in an interactive demonstration of memory capacity, the research used to discover such capacity has involved the use of computers. Thus, the demonstration has special fidelity because the student performs it by using essentially the same apparatus that was used in the original research. But there are differences that the student must understand. There are limits to memory capacity, and these limits exist whether or not they are assessed on a computer. Another subtle point is that, in the demonstration, the student must take some action to set up and initiate the experiment and must do something at its conclusion in order to get a summary of the data. Is it clear to the student precisely what parts of the demonstration session constitute the replication of what subjects saw and did in the original classic experiment? Does the student effectively disentangle the various aspects of the demonstration? (When I first began to use computer-based demonstrations in a cognitive psychology course, one demonstration required subjects in a perceptual task to report the contents of a briefly presented display. Student subjects were assigned to different conditions, and, for different subjects, the display was 
active for different lengths of time. One day a very upset student came to my office, saying that she had run the experiment four times, but was still "failing" the experiment since she was making only $30 \%$ correct responses. She had assumed that she would be graded on her performance, thereby missing the point of the demonstration. I had neglected to articulate both purpose and goals.)

Is the use of technology appropriate to the concepts to be learned? Sometimes someone produces a demonstration because it was a good programming exercise. However, the concept to be learned might be presented better either with a different technology, or, perhaps even better without technology. One example that comes to mind would be a demonstration of the McCollough aftereffect. Staring at a patch of color on a computer screen for 5 min may not be the best way to demonstrate the effect, in terms of either the effective use of the hardware, or the ability to obtain an effect strong enough to occur reliably. The fact that technology and software are available for addressing a particular problem does not mean that they should be used.

Is the technology used at the appropriate time in the course? For instruction to be effective, its use must proceed in an orderly fashion. When technology is used to demonstrate concepts, the demonstrations should be performed near the time at which the concepts are discussed in class. Little is gained by having the students do a demonstration before it has meaning or long after it is relevant. A lack of resources often results in spreading the use of the technology over time, with individual students completing a particular task at very different places in the course. But instructors must be very careful to ensure that the technology can be accessed appropriately and at the appropriate time in the course. To do a demonstration at the wrong time may be worse than not doing the demonstration at all.

Can the student use the technology to get an overview, do detailed study, and subsequently review the material? In an ideal world, students would approach the technology to get an introductory overview of the concept, return to the technology during the course of learning in order to refine their mastery and understanding, and be able to return again to the technology at a later time to review their understanding. Technology makes this multifaceted capability possible, and instructional materials should be designed to encourage it. Poor design is evident when, in order to review my mastery, I must again go through the (by now) trivial introductory material. (If I knew I had to do that, I would avoid the technology. Using a textbook, I can progress in different ways, but when I want to review the material in chapter $7, I$ am not forced to reread chapters 1-6.)

Does the technology facilitate appropriate collaborative learning? The evidence has been mounting for years that students learn much from each other. Does the technology encourage appropriate collaborative action or team effort? Not only can students learn many skills and concepts better in a collaborative environment, but work in the world beyond the campus is becoming more collabora- tive. Thus, students will also be developing a valuable skill that can serve them well later.

Does the technology encourage exploration, testing, and application of ideas and concepts? A learning environment is barren if it encompasses only the particular concept to be learned. We need to engage our students in the learning enterprise. At one extreme would be a simple glossary: One could require the student to memorize large numbers of facts and definitions, but that would be meaningless. The technology must enable the student to explore concepts and apply them to both abstract and real situations. Good technology enables the student to manipulate information to learn implications, to generate and test hypotheses, and to produce new information.

Does the technology permit appropriate self-assessment of comprehension? All of the prescriptions thus far deal with enabling the student to use the technology to manipulate and organize information. In an ideal world, learning environments would be crafted so students would always be aware of their achievement and understanding. But in practical terms, the students should be able to adequately assess their own achievement. Feedback is important so that the student can know whether more effort needs to be expended in learning a concept, or whether achievement is sufficient to let the student move on to master new concepts. Although we would like students to "self-monitor" their understanding, some form of validation is actually necessary.

Can the skills and concepts learned be transferred beyond the context in which the learning takes place? It is easy to find examples of how limiting our traditional instruction can be. For example, consider the students who complete a statistics course with a good grade and progress to an advanced laboratory course only to discover that they cannot conceive how to analyze the data from an experiment of their own design. Much of what we teach and learn is necessarily abstract, but what we learn must ultimately be applied-either in our personal lives or to advance the science. Does the technology encourage the transfer of knowledge to new contexts?

Computer-based games are often used to teach abstract concepts (Castellan, 1987b). Although we expect transfer to occur, it seldom happens spontaneously (Mayer, 1987). It is necessary to make the mapping from game or simulation to "real-life"' contexts explicit. The problem is that, as instructors, we are more or less expert in the subject, and we cannot easily see the task from the viewpoint of the student novice.

\section{Substantive Fidelity}

Substantive fidelity concerns the particular subject matter to be dealt with as one uses the technology. There are at least two issues to consider.

Is the material accurate? Surprisingly, people often assume that because something is written, it must be right. What is presented as factual material must match reality. A few years ago, I reviewed a simulation of animal behavior with which I was very impressed. It was well de- 
signed, it had effective graphics, and it had been tested for student mastery; but, as a colleague of mine pointed out, the simulated behavior was precisely the opposite of what had been reported in experimental studies of the behavior. Accuracy is crucial. Unfortunately, it too often goes unchallenged.

Moreover, because we have the capability to do new things with technology, we may quickly discover that the behavior we can simulate has never been studied experimentally with the factors and conditions that we can establish with the simulation or instructional technology. In such cases, we are faced with a dilemma-either we can do the actual research ourselves or we can prohibit the simulated occurrence. Both are undesirable. But there may be another option. Why not acknowledge the lack of knowledge and encourage students to hypothesize and support their arguments? This might be effective in some cases, but some have pointed out that playing with such artificial data and outcomes trivializes the whole research enterprise. They argue that if students can obtain fictitious data so easily, how confident will they be that real data are not fabricated? Or perhaps worse, students may infer that behavioral science data are completely arbitrary. This controversial problem is one that cannot be ignored in our classes.

Is the material worth learning? This question is seldom asked by instructional designers. Is the material crucial to the course or completely ancillary? When one has only one or two computer-based exercises in a course, they may take on-from the students' perspective-undue importance. Is the time allocated to mastering the material appropriate to its importance in the course of study? The judicious use of technology for parts of a course can be important in shaping students' evaluations of what is important.

\section{Integrative Flexibility}

Can the instructional software or technology be integrated into the course easily? Or, to put it another way: Can the course syllabus and/or the technology be modified to enable the resources to be used effectively? If the answer is no, I would argue that the technology should not be used. Instructional software-even if it consists only of a single package-must be assimilated within the course.

To be effective, the technology must not be seen as optional or as an aid for those who want "extra credit." The technology must be viewed by the students as an integral part of the course, and if they are to use it outside of the classroom, appropriate references must be made to it in lectures or class discussion. Terminology used in the software, lectures, technology, and text must be consistent. Finally, instructors must understand that adding instructional technology to the syllabus adds to the time that students must spend in the course. What can be eliminated? As we add tasks to the syllabus, we should delete other tasks that may have become less relevant to the course goals.
Finally, some attention should be given to the effect that the use of information technology in one course has on other courses. What one instructor does in one course can have implications for other courses. Ideally, one should deal not with a single course, but with the entire curriculum. This concern about integration is closely related to the concepts of horizontal and vertical integration as they apply to courseware development (see Castellan, 1984). Unfortunately, one seldom has the resources to deal with this matter, and departments often lack the political will to address more than a single course at a time.

\section{Cyclic Improvement}

Evaluations of instructional technology made before its use affect one course for one semester. But evaluations must be made during and after the course as well. The nature of the exercises and the instructional technology must be altered and modified as a result of experience in their use. If the technology appears to be less effective than desired, one must determine whether the problem lies in the technology, in the manner in which students use it, or in the manner in which it is integrated into the course.

\section{SUMMARY}

The goal of instructional technology is to increase the effectiveness of learning. This may involve engaging students' attention, teaching difficult concepts, or improving the efficiency of learning. Instructional technology is not neutral in this regard, but neither is it an end in itself. Several issues involving the effective use of information technology in instruction have been addressed. These issues can be organized into five types of strategic evaluation: technical accuracy, pedagogical soundness, substantive fidelity, integrative flexibility, and cyclic improvement. Within these categories of evaluation, issues have been phrased in terms of questions that the instructor or person responsible for the course should ask. There is no clear correct answer to these questions; rather, strategic evaluation is the search for answers to the questions in an instructional or learning context. Thus viewed, the successful integration of technology into one's courses is a continuing dynamic process of renewal and growth.

\section{REFERENCES}

Alessi, S. M., * TrolluP, S. R. (1985). Computer-based instruction: Methods and development. Englewood Cliffs, NJ: Prentice-Hall.

BAron, J. B., Sterngerg, R. J. (1987). Teaching thinking skills: Theory and practice. New York: W. H. Freeman.

Carroll, J. M. (Ed.) (1991). Designing interaction: Psychology and the human-computer interface. New York: Cambridge University Press.

Castellan, N. J., JR. (1984). A model for courseware development in psychology. Behavior Research Methods, Instruments, \& Computers, 16, 165-167.

Castellan, N. J., JR. (1986). Issues in the effective use of computers in introductory and advanced courses in psychology. Behavior Research Methods, Instruments, \& Computers, 18, 251-256.

Castellan, N. J., JR. (1987a). Computers and the shape of the fu- 
ture: Implications for teaching and learning. Education \& Computing, 3, 39-48.

Castellan, N. J., JR. (1987b). The use of computer-based games in teaching research methodology. Collegiate Microcomputer, 5, 209-212.

Castellan, N. J., JR. (1988). Comments on applications of microcomputers in teaching. Behavior Research Methods, Instruments, \& Computers, 20, 193-196.

DunCan, N. C. (1993). Evaluation of instructional software: Design considerations and recommendations. Behavior Research Methods, Instruments, \& Computers, 25, 223-227.

GAGNE, E. D. (1985). The cognitive psychology of school learning. Boston: Little, Brown.

Glover, J. A., Ronning, R. R., \& BrUning, R. H. (1990). Cognitive psychology for teachers. New York: Macmillan.

HiLL, W. E. (1982). Principles of learning: $A$ handbook of applications. Palo Alto, CA: Mayfield.
JONASSEN, D. H. (Ed.). (1988). Instructional designs for microcomputer software. Hillsdale, NJ: Erlbaum.

LoCkARD, J. (1992). Instructional software: Practical design and development. Dubuque, IA: W. C. Brown.

MAYER, R. E. (1987). Educational psychology: A cognitive approach. Boston: Little, Brown.

RANSDELL, S. (1993). Educational software evaluation research: Balancing internal, external, and ecological validity. Behavior Research Methods, Instruments, \& Computers, 25, 228-232.

SteinberG, E. (1991). Teaching computers to teach (2nd ed.). Hillsdale, NJ: Erlbaum.

TENNYSON, R. D. (1993). MAIS: A computer-based integrated instructional system. Behavior Research Methods, Instruments, \& Computers, 25, 93-100.

WELSH, J. A. (1993). The effectiveness of computerized instruction at the college level: Five suggestions for successful implementation. Behavior Research Methods, Instruments, \& Computers, 25, 220-222. 